\title{
Características da escola em tempo integral na Alemanha: um olhar analítico
}

\author{
Ilse Kamskil \\ Heike Schmitz" iD
}

\section{RESUMO}

Observa-se, no panorama educacional na Alemanha, uma reforma das escolas na última década. Houve um crescimento significativo de escolas que ofertam educação em tempo integral, que para sua implementação exige uma reorganização da instituição. Propõe-se aqui sistematizar, por meio de uma revisão da literatura científica alemã, características da escola em tempo integral com referência ao modelo de qualidade da escola em tempo integral de Holtappels, no qual são consideradas tanto a dimensão organizacional da instituição escolar como a pedagógica. Esse modelo apresenta um quadro de referência da qualidade para escolas em tempo integral no qual estrutura características, critérios e indicadores destacados por teorias educacionais e evidências empíricas.

\section{PALAVRAS-CHAVE}

escola em tempo integral na Alemanha; quadro de referência da qualidade da escola; desenvolvimento organizacional. 


\title{
CHARACTERISTICS OF THE FULLTIME-SCHOOL IN GERMANY: AN ANALYTICAL VIEW
}

\begin{abstract}
A school reform has been marking the German educational scenery in the last decade. There was a significant increase in the number of schools offering fulltime education. Their implementation requires a reorganization of schools. The aim is, through a review of the German scientific literature, to systematize characteristics of fulltime-schools, based on the quality model for fulltime-schools by Holtappels, which considers organizational and pedagogical dimensions of an organizational development of the fulltime school. Based on this, a reference Chart of quality for fulltime schools was developed, structuring characteristics, criteria and indicators evidenced by educational theories and empirical evidences.
\end{abstract}

\section{KEYWORDS}

fulltime school in Germany; reference frame of school quality; organizational development.

\section{CARACTERÍSTICAS DE LA ESCUELA A TIEMPO INTEGRAL EN ALEMANIA: UNA MIRADA ANALITICA}

\section{RESUMEN}

En el panorama educacional de Alemania se observa una reforma de las escuelas en la última década. Hubo un aumento significativo de escuelas que ofrecen educación a tiempo integral. Su implementación requiere una reorganización de la escuela. Se propone, en este caso, sistematizar, a través de una revisión de la literatura científica alemana, las características de la escuela a tiempo integral, con referencia al modelo de calidad de la escuela a tiempo integral de Holtappels, en el que es considerada tanto la dimensión organizacional como la pedagogía de la institución escolar y a partir de la cual se elaboró un cuadro de referencia de la calidad para las escuelas a tiempo integral, estructurando características, criterios e indicadores destacados por teorías educacionales y por evidencias empíricas.

\section{PALABRAS CLAVE}

escuela a tiempo integral en Alemania; cuadro de referencia de calidad de la escuela; desarrollo organizacional. 


\section{INTRODUÇÃO}

O que se compreende por uma escola em tempo integral na Alemanha, que formas de escola nesse modelo existem e quais são os critérios aplicados para avaliar sua qualidade? São essas as perguntas que nortearam este estudo, baseado em uma revisão bibliográfica cujo tema é o desenvolvimento organizacional da escola em tempo integral na Alemanha.

O cenário educacional alemão era predominantemente marcado por escolas que funcionavam em um único turno, comumente pela manhã. Em 2003, o programa federal Investitionsprogramm Zukunft, Bildung, Betreuung (IZBB) (Programa de Investimento Futuro, Educação e Acompanhamento) deu um impulso para a implementação da escola em tempo integral e, desde então, observa-se uma mudança significativa no panorama da educação naquele país. Em pouco menos de dez anos, cinquenta por cento das escolas alemãs passaram a oferecer uma jornada escolar ampliada (Rollett, 2014). No ano da implementação do IZBB, 6.268 escolas alemãs ofertaram seus serviços em tempo integral (KMK, 2009). Dez anos depois, em 2013, o número havia aumentado para 18.657 (KMK, 2015).

Também no Brasil se pode observar um aumento do número de escolas que ampliaram sua jornada escolar a partir da implementação de uma política pública em âmbito nacional, o Programa Mais Educação. Com a efetivação desse programa, cresceu o número de estabelecimentos públicos de educação básica com matrículas em tempo integral, de 14.808 (2007) para 43.816 (2012) (Parente, 2014). Isso significa um aumento percentual em seis anos de $8,93 \%$ do número total das escolas públicas em 2007 para 28,33\% em 2012. Com a aprovação da lei n. 13.005, de 25 de junho de 2014, que instituiu o atual Plano Nacional de Educação (PNE), estabeleceu-se a meta de que, até 2024, cinquenta por cento das escolas públicas do Brasil funcionem em tempo integral e atendam, no mínimo, a vinte e cinco por cento dos alunos matriculados na rede pública (Brasil, 2014).

As propostas de ambos os países, no entanto, não se restringiram a metas quantitativas referentes à expansão da escola em tempo integral. Esperavam-se, também, mudanças na oferta escolar, o que implica reorganizações tanto na proposta quanto no trabalho pedagógico da escola. Para transformar uma escola de tempo parcial em uma de tempo integral, exigiram-se, e ainda se exigem, reflexões acerca de reformas de características pedagógicas e organizacionais. Em outras palavras, é preciso esclarecer como se compreende a escola em tempo integral e como se define e avalia a sua qualidade.

Houve, na Alemanha, um interesse crescente a respeito da escola em tempo integral por parte de pesquisadores educacionais, inclusive motivado pelo Studie zur Entwicklung von Ganztagsschulen (StEG) (Estudo sobre o desenvolvimento de escolas em tempo integral), que acompanha cientificamente a sua implementação desde 2005. O StEG é uma análise com perfil longitudinal e de natureza quantitativa, que envolve perspectivas de diversos atores: gestores de escola, professores, pessoal extraescolar e parceiros da escola, assim como os próprios alunos e seus pais/responsáveis. 
Do ponto de vista científico, e também prático, em grande parte as escolas em tempo integral apresentam efeitos positivos, tais como a diminuição do risco de repetir o ano escolar; a diminuição de ocorrências de comportamento social problemático de alunos; e o aumento de ajuda para as famílias (Fischer et al.,2011). No entanto, existem também questões ainda não respondidas. O StEG revelou, por exemplo, efeitos (gerais e/ou diferenciados) sobre o desempenho do aluno e sua motivação, constatando que a participação nas ofertas em tempo integral não levou, automaticamente, a um aumento de motivação para estudar, à vontade de ir para a escola e à melhoria de desempenho. Há a presunção de que esses efeitos desejados dependem da cultura de aprendizagem e da participação de ofertas de um acompanhamento pedagógico individualizado (Fischer et al., 2011).

Diante da revelação do StEG de que os benefícios esperados da escola em tempo integral dependem de determinadas condições ou conjunto de fatores, tornou-se pertinente a busca por um norte analítico na questão do desenvolvimento organizacional da escola em tempo integral. Considera-se ferramenta útil um modelo sistêmico teórico que articula características organizacionais e pedagógicas da escola em tempo integral não só para categorizar os desafios a serem enfrentados na transformação da escola de tempo parcial em escola de tempo integral, mas também para orientar a instituição de ensino em seu desenvolvimento organizacional. Um modelo da qualidade da escola em tempo integral foi desenvolvido por Holtappels (2005). Esse modelo se estabeleceu no debate educacional da Alemanha e está sendo usado nas consultorias ofertadas para escolas em tempo integral (Kamski, Koltermann e Krinecki, 2013).

Mesmo reconhecendo que a realidade brasileira se diferencia da alemã, acredita-se que as reflexões teóricas sobre a implantação da escola em tempo integral naquele país podem contribuir também com o debate no cenário educacional do Brasil. Assim, busca-se, por meio da apresentação do referido modelo, enriquecer a discussão científica educacional em prol da educação em tempo integral brasileira. Para isso, são descritas brevemente, na primeira seção, concepções alemães da escola em tempo integral para, em seguida, apresentar suas características, categorizadas no modelo de Holtappels (2005), e o quadro de referência da qualidade para escolas em tempo integral, que atribui às características e aos critérios dessas escolas diversos indicadores para identificar sua qualidade.

\section{CONCEPÇÕES DA ESCOLA EM TEMPO INTEGRAL}

Os Kultusminister (secretários de cultura) dos estados da República Federativa da Alemanha, que têm soberania sobre assuntos de cultura e educação, formularam na Kultusministerkonferenz (Conferência dos Secretários da Cultura) um consenso mínimo sobre o que se compreende como escola em tempo integral. Definiu-se como modelo dessa escola uma instituição de ensino:

- que oferta, em pelo menos três dias semanais, uma jornada diária de sete horas (420 minutos) de ensino e atividades socioeducacionais para seus alunos; 
- que providencia, nos dias de jornada ampliada, almoço para os alunos matriculados;

- que oferece atividades em tempo integral sob responsabilidade da gestão escolar e realizadas em cooperação com e sob sua supervisão; e

- que articula as atividades extraclasse conceitualmente com o ensino em sala de aula (KMK, 2006).

Em virtude da natureza flexível desse conceito mínimo, existem na Alemanha três formas de realização da educação em tempo integral: aberta, obrigatória e parcialmente obrigatória. $\mathrm{Na}$ escola em tempo integral aberta são ofertadas atividades extraclasse em pelo menos três dias da semana, com sete horas diárias. Nessa modalidade, os pais/responsáveis podem (ou não) matricular os filhos em tempo integral, ou seja, eles podem decidir se o filho irá frequentar a escola em tempo parcial ou em tempo integral. Já na modalidade integral obrigatória, a oferta da educação em tempo integral ocorre em pelo menos três dias da semana, com sete horas diárias, para todos os alunos. Uma vez feita a opção por matricular o filho nessa escola, o aluno obrigatoriamente participará das atividades oferecidas em tempo integral. $\mathrm{Na}$ escola em tempo integral parcialmente obrigatória, a exigência de participar em tempo integral não se aplica a todos os alunos. Aqui a oferta acontece em pelo menos três dias da semana, com sete horas diárias, e pode estar direcionada para determinados alunos, ou determinadas turmas ou séries/anos. A escolha dos alunos que devem participar obrigatoriamente depende de critérios preestabelecidos, e os demais podem escolher matricular-se nas atividades extraclasse ofertadas, mas também podem decidir apenas frequentar o ensino regular.

Diante dessas três possíveis formas, distinguem-se cinco grupos de alunado:

1. alunos que voltam para casa depois do ensino regular;

2. alunos que continuam na escola, após a aula, apenas durante o almoço e o intervalo do meio-dia e depois voltam para casa;

3. alunos que usufruem, além do ensino em sala de aula e do almoço, também de um acompanhamento pedagógico de tarefas/deveres de casa, oferecido pela escola em tempo integral;

4. alunos que participam no ensino regular, no almoço, no acompanhamento das tarefas de casa e na oferta de atividades extraclasse; e

5. alunos que frequentam o ensino regular, vão almoçar em casa e retornam à escola para participar das atividades ofertadas no turno oposto.

A flexibilidade da definição da escola em tempo integral e as possíveis formas de implementá-la trazem implicações diretas na organização do trabalho pedagógico, considerando também que essas distintas formas de escola em tempo integral podem ser realizadas conforme dois diferentes modelos organizacionais, a saber: o modelo integrado e o modelo aditivo.

No modelo aditivo é oferecido o ensino regular em um turno, normalmente em sala de aula, e no turno oposto acontecem as atividades extraclasse. Essas atividades socioeducacionais podem ocorrer em sala de aula ou em outros espaços escolares (biblioteca, auditório/teatro, pátio, quadra, ginásio etc.), como também em 
espaços não escolares. Tal modelo é comum na escola em tempo integral de forma aberta. Em virtude do caráter voluntário da matrícula nas atividades extraclasse, não há garantias de que todo o alunado irá participar da oferta em tempo integral. Consequentemente, são constituídos diversos grupos de alunos, conforme antes descrito, e por isso só se pode oferecer acompanhamento pedagógico e atividades socioeducacionais no turno oposto.

No modelo integrado, as atividades extraclasse são mescladas e alteradas com as atividades regulares de ensino em um único turno. É possível organizar esse modelo em uma escola obrigatória em tempo integral, uma vez que todo o alunado participa da jornada escolar em tempo integral. A participação de todos os alunos facilita a organização do trabalho pedagógico em tempo integral, beneficiando a articulação entre conteúdo de sala de aula e atividades extraclasse.

Também em outros aspectos pedagógicos se torna enriquecedor o modelo integrado, pois se pode organizar um novo ritmo para o cotidiano escolar. Como todo o alunado frequenta a escola na jornada ampliada, é possível organizar novos arranjos para o dia escolar com a combinação de atividades regulares e extraclasse, em vez de uma separação em turno e contraturno. Pode-se permitir um ritmo que alterna fases de esforços, atenção e tensão com fases de descontração e relaxamento; um novo ritmo que também facilita a troca entre aulas expositivas e/ou interativas com atividades em projetos, trabalho autônomo do aluno, grupos de estudos, entre outros.

$\mathrm{Na}$ escola parcialmente obrigatória, na qual determinados alunos participam obrigatoriamente e outros voluntariamente da educação em tempo integral, encontram-se, semelhante à escola com forma aberta, mais dificuldades para organizar esse novo ritmo do dia escolar. Contudo existem escolas em tempo integral na Alemanha que criaram estratégias mistas, ou seja, parcialmente aditiva ou parcialmente integrada. Por exemplo, pode-se definir em cada série/ano escolar uma turma que participa obrigatoriamente na oferta em tempo integral. As demais funcionam em tempo parcial, ou seja, em apenas um turno do dia. Para os alunos matriculados na turma da educação em tempo integral, pode-se organizar o ritmo do dia escolar diferenciado, conforme o modelo integrado, isto é, podem ser mescladas ou alteradas as atividades do ensino regular e da oferta extraclasse. No almoço, na oferta do acompanhamento pedagógico e nas atividades socioeducacionais que ocorrem no turno oposto do ensino regular, também os alunos que estão matriculados na escola apenas em tempo parcial podem se cadastrar voluntariamente, desde que haja vagas.

A implementação da educação em tempo integral, contudo, não se restringe à escolha ou indicação de determinado modelo ou forma. É necessário também ganhar clareza sobre as características específicas que distinguem uma escola em tempo integral de uma escola em tempo parcial. A implementação da educação escolar em tempo integral abrange mudanças administrativas e organizacionais, como também mudanças de natureza pedagógica que se referem aos processos de ensino e aprendizagem. Por isso, é imprescindível um desenvolvimento sistemático da própria organização do ensino. 


\section{O DESENVOLVIMENTO ORGANIZACIONAL DA ESCOLA EM TEMPO INTEGRAL}

A escola em tempo integral se diferencia da escola em tempo parcial por diversas características, por exemplo, como anteriormente mencionado, pela possibilidade de distribuição das atividades escolares durante o dia inteiro (manhã e tarde) e de implementação de um novo ritmo para a dia escolar, em que se alternam atividades tensas e de relaxamento.

Diversos autores abordam tais características. De acordo com Ipfling (1988), a escola em tempo integral caracteriza-se pela integração de exercícios no ensino de sala de aula; pela suspensão ou, pelo menos, diminuição das tarefas/deveres de casa; pela disponibilização de momentos para relaxar (principalmente para alunos do primeiro ciclo do ensino fundamental), da oferta de lazer e de atividades lúdicas; pela oferta pedagógica diversificada conforme aos interesses específicos do grupo de alunos; pela atuação de assistentes sociais e/ou pais/responsáveis em determinadas áreas da escola; e, por último, mas não menos importante, pela oferta do almoço.

Também Bargel e Kuthe (1991) descrevem esses elementos da estrutura básica de uma escola em tempo integral, abordados por Ipfling (1988). Os autores discutem o acompanhamento pedagógico das tarefas/deveres de casa e exercícios, o acompanhamento pedagógico individual para combater deficiências e fortalecer talentos, a oferta de atividades socioeducacionais organizadas por meio de matrícula em oficinas e grupos de trabalhos e a oferta de atividades de lazer, como esportes, jogos, atividades com fins de relaxamento, nas quais os alunos possam participar por escolha própria, além do almoço ofertado na escola. A essas características da escola em tempo integral listadas, Ludwig (2003) ainda acrescenta outras: a abertura da escola para seu meio social e as mudanças do papel do professor.

Holtappels (1994) apresentou um modelo que organiza diversas características, inclusive abrangendo mais que as antes listadas. Desde então, o modelo foi aprofundado e desenvolvido, dividindo tais particularidades em duas dimensões: pedagógica e organizacional. No entanto, o autor alerta sobre o fato de que o desenvolvimento organizacional sistemático de uma escola em tempo parcial sempre abrange ambas as dimensões para que se possa tornar uma escola em tempo integral de qualidade.

A dimensão organizacional da escola envolve, conforme Holtappels (2005 apud Kamski, 2011), seis características. São elas: a gestão de pessoas (organização e desenvolvimento); a abertura institucional da escola (parcerias); a participação de alunos e pais/responsáveis em processos de tomada de decisão; a organização e configuração de espaços; o fornecimento de refeições e catering; e a organização de tempo e novo ritmo do dia escolar.

No que diz respeito à gestão de pessoas, a instituição de ensino vê-se diante do desafio de reorganizar os horários de professores, mas também de integrar novos atores no ambiente escolar, pois se espera que o coletivo de pessoas que atuam na escola em tempo integral se componha não apenas de professores e funcionários, mas também de profissionais de diversas áreas. Assim, nesse coletivo se juntam pessoas com diferentes graus de formação, com compensação salarial diferenciada, 
com variados vínculos com a escola, estabelecidos por diferentes formas de contratos (concursado, contratado, voluntário). Além disso, cada pessoa se envolve na educação em tempo integral com base em uma compreensão individual sobre o que ela entende por educação (integral) e o que ela pessoalmente pretende contribuir com esse modelo. Dito de outra forma, no coletivo da escola, há perspectivas múltiplas sobre o que é educação (em tempo integral). Para o desenvolvimento organizacional, a gestão escolar tem a tarefa de alinhá-las a uma visão compartilhada em benefício do bem-estar da criança e do adolescente.

Iniciar e consolidar as cooperações entre atores escolares e parceiros não escolares a favor da abertura da escola para o mundo da vida dos alunos é outro aspecto central da dimensão organizacional. Justamente para que esse mundo seja experimentado na prática pelo aluno, é preciso uma abertura da escola para o seu entorno social. Porém essa abertura e a busca de parceiros de cooperação implicam também a necessidade de elucidar as expectativas mútuas e estabelecer claramente a exigência de competências e responsabilidades cobradas de cada lado, ou seja, dos atores escolares e dos extraescolares.

O mesmo vale para a participação dos alunos e pais/responsáveis na vida escolar. Porque, para ensinar cidadania, ou seja, ajudar o aluno a tornar-se um cidadão crítico, ativo e responsável pela comunidade (escolar e local), é preciso promover oportunidades de participação em que ele possa desenvolver o senso de responsabilidade e um agir democrático.

Isso, contudo, exige ambientes adequados na escola. A instituição escolar precisa disponibilizar espaços para ensino em sala de aula, atividades socioeducacionais, almoço coletivo, mas também espaços adequados para trabalhos individuais e estudos coletivos, atividades de movimento, de relaxamento, e para experiências sociais.

O desenvolvimento organizacional abrange também a organização do próprio dia escolar. A escola em tempo integral pode, como afirmado anteriormente, implementar um novo ritmo para as atividades por causa da ampliação do tempo da jornada. Já nos anos de 1960, compreendeu-se a reestruturação do dia escolar do aluno como uma oportunidade de reconsiderar aspectos organizacionais, como também pedagógicos e de saúde (Lohmann, 1965; Ludwig, 1993). Não é preciso mais, necessariamente, assegurar a aula de 45 minutos. Pode-se aumentar ou diminuir o tempo de aula para adaptar o ensino a novas possibilidades didáticas e metodológicas em prol de melhores condições no processo de aprender do discente. Com base em uma visão compartilhada e um esforço coletivo, pode-se, por exemplo, integrar atividades de ensino de habilidades práticas, assim como atividades lúdicas na aquisição de saberes. A integração de pedagogia de projetos e da pedagogia de lazer é, conforme Rekus (2003), uma rica oportunidade na reorganização do desenvolvimento de ensino e aprendizagem - até mesmo mais fácil de operacionalizar, como foi dito, em uma escola que mescla atividades do ensino regular com atividades extraclasse durante a jornada diária, ou seja, que funciona em um turno único.

Rekus (2003) introduz o conceito do "erziehender Unterricht" (ensino educacional), composto por três formas de ensino: o ensino de matérias (conteúdo de curso); o ensino por meio de projetos; e o trabalho autônomo. $\mathrm{O}$ ensino de matérias, que é predominantemente centralizado no professor e orientado na qualificação do 
aluno, focaliza na competência cognitiva de conteúdo. Precisa-se desse tipo de ensino para preparar o aluno às demandas da sociedade e do mercado de trabalho, chamando sua atenção também para a responsabilidade na realização de suas próprias atividades escolares e extraclasse. Já no ensino por meio de projetos interdisciplinares e transdisciplinares, orientados em valores e no próprio aluno, o foco é no desenvolvimento de uma visão e compreensão críticas do aluno acerca do contexto social no qual ele está inserido. Justifica-se esse tipo de ensino porque o aluno precisa da capacidade de avaliar e julgar a situação como condição de agir. Para isso ele precisa aprender a ganhar consciência sobre sua própria situação, sua opinião/postura diante dela e sua atitude. E no trabalho autônomo o estudante adquire a capacidade de tomar decisões e agir. $\mathrm{O}$ aluno, tendo a livre escolha entre tarefas, processos e formas de trabalhos, como também a livre escolha de como organizar o tempo para realizá-lo, aprende a desenvolver a competência de autorresponsabilidade e de autodeterminação. Esse tipo de ensino é preciso para poder lidar com uma vida autônoma e responsável. A escola em tempo integral precisa criar cada vez mais oportunidades para que se desenvolva essa nova cultura de aprendizagem - isso porque o aluno, em virtude do maior tempo que permanece diariamente nela, terá menos acesso a outros espaços sociais e oportunidades de aprendizagem.

A oferta do almoço coletivo para os alunos matriculados na educação integral é outro desafio organizacional e, ao mesmo tempo, um desafio pedagógico. O fornecimento do almoço se compreende como um momento pedagógico, pois é quando se tem a oportunidade de orientar não só acerca de hábitos de alimentação em benefício da saúde do aluno, como também sobre regras sociais.

$\mathrm{Na}$ dimensão pedagógica existem, conforme Holtappels (2005), sete características que marcam uma escola em tempo integral. $\mathrm{O}$ autor, como já fizeram Ipfling (1988) e Bargel e Kuthe (1991), refere-se ao acompanhamento pedagógico individual para promover o aluno; às atividades lúdicas e de lazer; à ampliação de oportunidades de aprendizagens conforme interesses e talentos dos alunos; e à abertura da escola. Além disso, atribui à escola em tempo integral as características de uma nova cultura de aprendizagem, de participação e aprendizagem democrática e de aprendizagem social comunitária.

No que diz respeito à característica do ensino em sala de aula e da cultura de aprendizagem, a escola em tempo integral adapta o processo de ensino e aquisição de saberes às demandas e necessidades dos alunos e aos novos conhecimentos científicos por meio de novos arranjos pedagógicos e metodológicos, abrindo mão da ênfase no ensino de disciplinas. O desenvolvimento de novas práticas de ensino também se reflete na característica da promoção e do acompanhamento individual. $\mathrm{Na}$ escola em tempo integral, há uma preocupação de se oferecer acompanhamento mais individualizado e ampliar as oportunidades de aprendizagens, promovidas por meio de ofertas adequadas ao perfil do alunado objetivando potencializar esses momentos para todos.

Caracteriza-se a escola em tempo integral por sua abertura para o mundo além dela. A ampliação do dia escolar permite e/ou facilita organizar atividades que deixam a realidade dos alunos penetrar os muros da escola. Essa abertura, além disso, leva à ampliação de oportunidades de aprendizagens também fora da escola, 
como quando se realizam visitações a museus, ou outros estudos do meio, ou com a dinâmica de trabalho com projetos, que se podem configurar como ofertas adequadas aos interesses dos alunos e às suas habilidades. Nessas novas oportunidades de educação, podem-se até mesmo descobrir potenciais de aprendizagem dos alunos que antes ficavam encobertos.

No que diz respeito à característica da comunidade e aprendizagem social, a escola em tempo integral destaca-se por oferecer tais possibilidades em momentos distintos que se oferecem em um dia escolar ampliado. Em coletividade/comunidade, por exemplo, durante o almoço, como também em atividades de lazer ou eventos comunitários, é possível fortalecer relações sociais e desenvolver as competências sociais dos alunos.

A oferta de atividades de lazer e de atividades lúdicas na escola em tempo integral pode garantir a possibilidade de o aluno escolher com autodeterminação, ou seja, é o aluno quem decide de quais atividades quer participar, desenvolvendo assim sua autonomia. Elas podem ser organizadas, por exemplo, em forma de oficinas e grupo de trabalhos ou até de maneira não dirigida. Nesse último caso, os alunos brincam entre si sem o direcionamento de um adulto responsável.

Diante do fato de que o aluno passa o dia inteiro envolvido em atividades organizadas ou ofertadas pela escola, também se exige uma reflexão sobre as tarefas/deveres de casa. Parece plausível transformar as tarefas/deveres de casa em exercícios escolares, cumpridos pelo aluno durante o tempo em que ele frequenta a escola. A função da tarefa de casa, isto é, o exercício, pode ser integrado no próprio ensino em sala de aula e/ou em momentos de estudos, como no acompanhamento pedagógico individual.

Apostar na educação em tempo integral como estratégia de melhoria da qualidade da educação exige reflexões sobre a reorganização do trabalho pedagógico da escola e, consequentemente, investimento na adequação das escolas em infraestrutura e recursos pedagógicos e na adequação e disponibilização da própria oferta pública do município em matéria de, entre outros, biblioteca pública, teatros, praças, museus, e segurança para garantir que se possa usufruir desses espaços. Para o desenvolvimento da escola em tempo integral, o modelo de Holtappels (2005) parece ser uma ferramenta útil para auxiliar não só os gestores escolares, mas também os atores políticos e cientistas a enfrentar a complexidade de sua implementação e consolidação com qualidade. O modelo de Holtappels é um norte analítico na questão do desenvolvimento organizacional da escola, atentando às suas características organizacionais e pedagógicas, contudo sem desconsiderar as condições sistêmicas e estruturais em que está inserida e seus resultados, ou seja, sua eficácia.

\section{QUADRO DE REFERÊNCIA DA QUALIDADE PARA ESCOLAS EM TEMPO INTEGRAL}

Holtappels, Kamski e Schnetzer (2009) elaboraram um quadro de referência da qualidade para escolas em tempo integral que traduz o modelo em indicadores. Consideram, para tal, argumentos teóricos e evidências de pesquisas, 
reconhecendo, por um lado, a qualidade da educação em tempo integral já ofertada e, por outro, estimulando a revitalização de um debate acerca desse modelo educacional. Percebe-se, diante disso, que se trata de um quadro dinâmico, porque características e critérios podem ser mudados ou modificados com o decorrer de novas evidências científicas.

O quadro foi organizado em três fases: qualidade do sistema/estrutura; qualidade da configuração e dos processos; e qualidade dos resultados. Atribuíram-se a cada fase dimensões de qualidade que abrangem características às quais são associadas critérios. Esses critérios, por sua vez, envolvem conjuntos de indicadores. No total, o quadro reúne 338 indicadores, sendo 53 referentes à dimensão da qualidade do sistema e da estrutura, 230 referentes à dimensão da qualidade do processo e 55, à dimensão da qualidade dos resultados.

Em virtude da complexidade do quadro, não cabe aqui descrever todos os indicadores, mas para exemplificar serão apresentados alguns da fase da qualidade do sistema/estrutura, porque nela também foram incorporadas as condições contextuais. Assim, essa fase também inclui aspectos relevantes não só para gestores de escolas, como também para as redes mantenedoras.

Percebe-se que nessa fase as escolas têm um espaço de tomada de decisão e de ação limitados, principalmente no que diz respeito às condições organizacionais e de infraestrutura. São as redes mantenedoras e os atores políticos que definem e configuram essas condições como ponto de partida para a implementação da educação em tempo integral. Consequentemente, a qualidade da escola em tempo integral não depende apenas da instituição de ensino, mas também dos atores políticos que formulam suas diretrizes organizacionais e definem a distribuição de recursos a serem destinados a ela. Já com relação ao uso de apoio externo e redes de cooperação, a escola tem um poder maior de ação, desde que tais apoios e redes estejam sendo providenciados pelas políticas educacionais ou de outros setores. (Holtappels, Kamski e Schnetzer, 2009).

$\mathrm{Na}$ fase da qualidade do sistema e da estrutura se distinguem três dimensões:

1. condições organizacionais;

2. infraestrutura e equipamento; e

3. condições estruturais do contexto.

As características da dimensão das condições organizacionais são:

- as diretrizes organizacionais;

- as normas organizacionais; e

- a estruturação do tempo.

A dimensão da infraestrutura da escola abrange:

- disponibilidade de espaços;

- pessoas; e

- recursos materiais.

E, finalmente, na terceira dimensão da qualidade do sistema, cabem as condições estruturais do contexto, no qual se articulam como características: 
- o sistema de apoio externo para as escolas; e

- as redes de cooperação regionais.

A cada caraterística são associados diversos critérios, e para estes são formulados indicadores. A respeito das características concernentes às diretrizes organizacionais, estas são subdivididas em três critérios:

1. escola em tempo integral obrigatório;

2. escola em tempo integral obrigatória parcialmente;

3. escola em tempo integral aberta.

Holtappels, Kamski e Schnetzer (2009) listam, por um lado, indicadores que se referem diretamente àqueles aspectos que são implícitos na própria definição de cada forma de escola. Indicam, por exemplo, a qualidade de uma escola em tempo integral, se todos os alunos participam de sete horas na oferta escolar em tempo integral, que acontece em pelo menos três dias da semana, e se há uma articulação do ensino regular e da oferta extraclasse garantida de forma organizada e registrada no projeto pedagógico da escola.

Por outro lado, juntam-se, associadas a essa característica, indicadores como o aproveitamento da possibilidade de um novo ritmo no nível da escola, da sala de aula e no nível do aluno; o alcance de uma taxa de participação de alunos de pelo menos 30\% (em virtude da diversidade da oferta e das possibilidades adequadas à idade dos alunos); o esforço para permitir uma integração de alunos com diferentes desempenhos escolares e oriundos de distintos contextos socioeconômicos.

Aqui ganha ênfase a questão do tempo na escola. Diante do aumento de demandas a respeito do ensino de competências e habilidades, a escola precisa recorrer a uma proposta pedagógica bem projetada, que abranja tanto um apoio intenso para a aprendizagem do alunado, quanto uma oferta diferenciada de métodos de ensino e de aquisição de saberes e uma concepção própria do tempo estendido da aprendizagem (Schnetzer, 2009).

A característica estruturação do tempo subdivide-se em nove critérios:

1. extensão do tempo;

2. concepção e cooperação;

3. tempo do ensino regular;

4. tempo para acompanhamento pedagógico;

5. oferta de atividade de lazer obrigatória e voluntária;

6. oportunidades ampliadas de aprendizagem;

7. comunidade e aprendizagem social;

8. participação; e

9. abertura da escola.

Holtappels, Kamski e Schnetzer (2009) consideram, por exemplo, como indicadores de qualidade para o critério da concepção e cooperação de uma escola em tempo integral se ela tem horários fixos para o planejamento educacional em benefício do novo ritmo do dia escolar; se há, institucionalmente, horários fixos para (reuniões de) cooperação entre professores, entre professores e atores não escolares e para os atores não escolares entre si. 
Como alerta Schnetzer (2009), a extensão de tempo significa também uma extensão de força de trabalho e recursos. Essa demanda está sendo cumprida em muitas escolas em tempo integral na Alemanha, por meio de uma cooperação com parceiros não escolares. São justamente esses atores não escolares que podem enriquecer a oferta com seus saberes profissionais no âmbito da pedagogia de lazer, e também com suas experiências práticas oriundas de diversos campos de conhecimento. Esses parceiros de cooperação são associações, clubes e instituições, assim como pessoas físicas. Mas não é a diversidade da oferta ou dos parceiros em si que garante a qualidade da escola em tempo integral. É o acoplamento da oferta extraescolar com o ensino regular.

Partindo da compreensão de que a cooperação é um sistema funcional de ações entre duas ou mais pessoas com determinados objetivos coletivos (Sonnentag, Fay e Frese, 2004), precisa-se, no contexto da escola em tempo integral, de uma definição clara desses objetivos. Para garantir a articulação do ensino regular e da oferta extraclasse como indicador de qualidade da escola em tempo integral, a cooperação entre atores escolares e não escolares precisa ser coordenada pela escola com vistas às demandas e necessidades da instituição e dos alunos.

Assim, Holtappels, Kamski e Schnetzer (2009) também consideram como indicador associado à característica da estruturação do tempo se a escola garante acompanhamento pedagógico específico, conforme os diferentes níveis de desempenhos dos alunos, tanto de forma integrada em sala de aula do ensino regular quanto em horários extras.

Ainda acerca da mesma fase do quadro de referência, isto é, da qualidade do sistema e da estrutura, cabem reflexões no que diz respeito à segunda dimensão: as condições organizacionais (infraestrutura e equipamento) da escola em tempo integral. É preciso adaptar o ambiente físico da escola porque as crianças e os jovens precisam ter um espaço adequado, não só a sua idade, mas também às atividades previstas. A essa dimensão, Holtappels, Kamski e Schnetzer (2009) associam, por isso, as características: disponibilidade de espaços; pessoas; recursos materiais, que são subdivididos de acordo com os seguintes critérios:

- salas de aula;

- espaço de alimentação;

- espaço para encontros sociais;

- espaço para poder se retirar;

- espaço de mídias e biblioteca;

- espaço de movimentos e jogos;

- espaço para experiências sociais;

- espaço para arte e técnica;

- áreas do pessoal;

- gestão de pessoas;

- soberania de pessoal;

- recursos do mantenedor da escola;

- recursos para projetos; e

- doações e sponsoring. 
Nesse sentido, os autores anteriormente citados juntam indicadores de qualidade tais como: lugares para nichos, arranjos de assentos para grupos pequenos (e.g., por meio de paredes divisórias, móveis nas salas), poltronas/colchões para deitar (ensino fundamental I), lugares para sentar no pátio; midiateca, oficina de aprendizagem, cyber café, biblioteca de lazer; auditórios, salas para projetos, grêmio estudantil, oficinas artesanais, hora, anfiteatro, espaço para construção com madeira etc.; cozinha de aprendizagem, oficina de costurar, oficina de cerâmica, oficina de tecer, oficinas de artesanatos com madeira, metal, oficina de bicicleta ou motos; sala de professores e atores não escolares e um espaço de descanso para o pessoal.

No que se refere à característica pessoas, chamam atenção os indicadores se também se consideram na distribuição das quotas de horas de trabalho semanal (dos professores e do pessoal) o tempo para a concepção e o planejamento da educação em tempo integral; se a equipe gestora da escola tem autonomia para escolher seu pessoal; se na escola são estabelecidos procedimentos funcionais de recrutamento de pessoal; e se há medidas adequadas para integrar, capacitar e profissionalizar a pessoa não escolar (e.g., por meio de participação em cursos de formação continuada). A respeito da caraterística recursos materiais, esse é um indicador da qualidade da escola, entre outros, se a equipe gestora tem um projeto para solicitar doações e sponsoring para aplicá-las conforme planos estabelecidos e as administra de modo transparente.

A última dimensão articulada à fase da qualidade do sistema e estrutura é a das condições estruturais do contexto com suas duas características: apoio externo para as escolas e redes de cooperação regionais. Nesse caso, chamam atenção indicadores como a construção de redes entre escolas ou a visitação mútua entre escolas em tempo integral para a troca de experiências, conhecimentos, métodos e instrumentos, quebrando a luta solitária de cada escola, objetivando melhorias. Recorrer a um apoio externo torna-se útil também no estabelecimento de uma comunicação e do entendimento acerca dos objetivos da escola em tempo integral e na criação de um fio norteador pedagógico e organizacional tanto para os atores escolares quanto para os não escolares que nela atuam ou que com ela cooperam.

Optou-se por apresentar essa terceira dimensão de maneira gráfica, mantendo, assim, o formato do quadro que Holtappels, Kamski e Schnetzer (2009) elaboraram. Dessa forma, os autores permitem uma gestão em um relance (at a glance), com fácil uso para gestores escolares, visto que a forma gráfica pode ser compreendida não só como síntese, mas também como um checklist, para não perder de vista quanto a escola já conseguiu realizar e o que mais poderá ser feito. Como é possível observar, o Quadro 1 ilustra a divisão em dimensão, características, critérios e indicadores.

Cabia aqui apenas a discussão de uma das três fases contempladas no quadro de referência da qualidade para escolas em tempo integral, e ainda assim só a apresentação gráfica de uma parte dessa fase. Os autores apresentaram o quadro de referências na íntegra, tanto em publicações científicas como também como instrumento de consultoria a escolas (Holtappels, Kamski e Schnetzer, 2009). 


\section{CONSIDERAÇÕES FINAIS}

A escola em tempo integral na Alemanha define-se, conforme o consenso mínimo dos secretários de cultura dos estados da República Federativa da Alemanha, pelas atividades que articulam o ensino regular e a oferta socioeducacional, pelo diálogo entre diversas culturas e saberes comunitários e escolares, oferecidos em uma jornada escolar prorrogada. $\mathrm{Na}$ busca por formas de escolas que operacionalizam os critérios fixados na definição oficial, também houve a preocupação de não limitar a soberania educacional dos pais/responsáveis. Foram pensadas formas que consideram o direito dos pais/responsáveis de optar por matricular os filhos em uma oferta educacional em tempo parcial ou integral. Dessa maneira, implementou-se a educação em tempo integral na Alemanha sem grandes resistências.

Ao mesmo tempo, a flexibilidade do consenso mínimo da definição oficial garantiu que cada escola pudesse escolher um modo de operacionalização mais adequado as suas condições. Para oferecer uma educação em tempo integral, a escola na Alemanha pode escolher entre três formas e entre dois modelos. As três formas são: escola em tempo integral aberta, escola em tempo integral obrigatória e escola

\section{Quadro 1 - Fase qualidade do sistema e da estrutura: indicadores referentes à dimensão das condições estruturais do contexto, distribuídos por critério e característica.}

\begin{tabular}{|c|c|c|}
\hline Características & Critérios & Exemplos de indicadores \\
\hline \multirow{5}{*}{$\begin{array}{l}\text { Sistemas externos } \\
\text { de apoio }\end{array}$} & \multirow{5}{*}{$\begin{array}{l}\text { Desenvolvimento } \\
\text { e } \\
\text { operacionalização } \\
\text { da concepção }\end{array}$} & $\begin{array}{l}\text { A escola recebe apoio externo (e.g., consultoria para escolas } \\
\text { em tempo integral, consultoria na elaboração do projeto } \\
\text { pedagógico) para o desenvolvimento da concepção da } \\
\text { educação em tempo integral. }\end{array}$ \\
\hline & & A escola visita outras escolas para coletar ideias. \\
\hline & & $\begin{array}{l}\text { Parte do corpo docente participa de cursos de formação } \\
\text { continuada no que diz respeito ao desenvolvimento e } \\
\text { operacionalização da concepção da educação em tempo } \\
\text { integral e compartilha seu conhecimento, conforme } \\
\text { critérios preestabelecidos, com os demais colegas. }\end{array}$ \\
\hline & & $\begin{array}{l}\text { Em encontros (do planejamento pedagógico), moderados por } \\
\text { consultores, a comunidade escolar (incluindo alunos e pais/ } \\
\text { responsáveis) acompanha um desenvolvimento sistemático de } \\
\text { concepção, cada vez sob determinado foco temático. }\end{array}$ \\
\hline & & $\begin{array}{l}\text { A escola participa de eventos científicos (seminários, } \\
\text { congressos) com temáticas afins. }\end{array}$ \\
\hline \multirow{2}{*}{$\begin{array}{l}\text { Redes de } \\
\text { cooperação regionais }\end{array}$} & Redes escolares & $\begin{array}{l}\text { A escola participa de uma rede entre escolas, constituída por } \\
\text { um conjunto de regras, para os devidos fins de intercâmbio } \\
\text { de experiências, conhecimento, métodos e instrumentos. }\end{array}$ \\
\hline & $\begin{array}{l}\text { Panorama } \\
\text { educacional } \\
\text { regional }\end{array}$ & $\begin{array}{l}\text { A escola participa de uma rede ou sistema de intercâmbio } \\
\text { composto de atores importantes do entorno social da escola. }\end{array}$ \\
\hline
\end{tabular}

Fonte: Holtappels, Kamski e Schnetzer (2009, p. 64-65, tradução nossa).

Elaboração das autoras. 
em tempo integral parcialmente obrigatória. Além disso, pode-se então optar por um modelo integrado que mescla ensino regular e oferta extraclasse durante o dia escolar, ou escolher um modelo aditivo, que funciona em turno e contraturno, para oferecê-los respectivamente.

Em termos pedagógicos, o modelo aditivo de uma escola em tempo integral dificulta a organização do trabalho pedagógico, pois limita a oportunidade de melhor articulação conceitual do ensino e atividades socioeducacionais e a implementação de inovações pedagógicas, de uma nova cultura de aprendizagem. E são essas, entre outras, as características desejadas para a escola em tempo integral na Alemanha.

É possível resumir, sem intenção, contudo, de sugerir uma ordem de prioridades, as seguintes características atribuídas por Holtappels (2005) a dimensões pedagógica e organizacional da escola em tempo integral. Como centrais características organizacionais se consideram:

1. a gestão e a formação do pessoal multiprofissional;

2. a abertura institucional da escola e a cooperação com parceiros não escolares;

3. a participação de alunos e seus pais/responsáveis em processos de tomada de decisão;

4. a organização e a configuração de espaços (escolares e não escolares);

5. a concepção de alimentação/nutrição e do almoço coletivo;

6. a configuração do dia escolar e o novo ritmo do dia escolar.

Já à dimensão pedagógica se atribuem as características:

1. a organização da aprendizagem e nova cultura de aprendizagem (exercícios integrados em vez de tarefa para casa);

2. o acompanhamento individual do aluno;

3. a contextualização do ensino;

4. a aprendizagem social e intercultural;

5. a aprendizagem de democracia;

6. a ampliação de oportunidades de aprendizagem orientadas nos interesses e talentos dos alunos; e

7. a oferta de lazer e a concepção do intervalo (pedagogia de projetos e pedagogia de lazer).

Vale destacar que o desenvolvimento organizacional ocorre no âmbito da própria instituição de ensino. Por isso essa categorização de características de uma escola em tempo integral, se for definida, aprofundada e diferenciada in loco, ou seja, na própria escola, com a participação dos atores envolvidos ou seus representantes, pode tornar-se uma ferramenta útil no desenvolvimento sistemático.

Para ter em vista a complexidade do empreendimento de ampliar a jornada escolar em prol do desenvolvimento pleno do aluno, serve o quadro de referência da qualidade para escolas em tempo integral. Nele são propostos 338 indicadores referentes às diversas características aqui discutidas, porém Holtappels, Kamski e Schnetzer (2009) ressaltaram o caráter dinâmico do quadro no qual, conforme novos conhecimentos teóricos e novas evidências 
empíricas, o conjunto de indicadores se modificará e pode nortear tanto as políticas educacionais em favor da educação em tempo integral como também os atores escolares em sua operacionalização.

\section{REFERÊNCIAS ${ }^{1}$}

Bargel, T.; Kuthe, M. (Orgs.). Ganztagsschule: Untersuchungen zu Angebot und Nachfrage, Versorgung und Bedarf. Bonn: K. H. Bock, 1991. [Escola em tempo integral: estudos sobre a oferta e demanda]

Brasil. Lei n. 13.005, de 25 de junho de 2014. Aprova o Plano Nacional de Educação PNE e dá outras providências. Diário Oficial da União, Brasília, DF, 26 jun. 2014.

Fischer, N. et al. Ganztagsschule: Entwicklung, Qualität, Wirkungen: Längsschnittliche Befunde der Studie zur Entwicklung von Ganztagsschulen (StEG). Weinheim: Juventa, 2011. [Escola em tempo integral: desenvolvimento, qualidade, efeitos: resultados longitudinais do estudo sobre o desenvolvimento de escolas em tempo integral (StEG)] Holtappels, H. G. Ganztagsschule und Schulöffnung: Perspektiven für die Schulentwicklung. Weinheim: Juventa, 1994. [Escola em tempo integral e abertura da escola: perspectivas para o desenvolvimento de escolas]

. Ganztagsschulen entwickeln und gestalten: Zielorientierungen und Gestaltungsansätze. In: HöHmann, K. et al. (Ed.). Entwicklungs und Organisation von Ganztagsscbulen: Anregungen, Konzepte, Praxisbeispiele. Dortmund: IFS-Verlag, 2005. p. 7-44. [Desenvolver e configurar escolas em tempo integral: orientação em objetivos e abordagens de configurações] [Desenvolvimento e organização de escolas em tempo integral: sugestões, concepções e exemplos da prática]

Holtappels, H. G.; Kamski, I.; Schnetzer, T. Qualitätsrahmen für Ganztagsschulen. In: Kamski, I.; Holtappels, H. G.; Schnetzer, T. Qualität von Ganztagsschule: Konzepte und Orientierungen für die Praxis. Münster: Waxmann, 2009. p. 61-88. [Quadro de referência para a qualidade de escolas em tempo integral] [Qualidade da escola em tempo integral? Concepções e orientações para a prática]

IpfLING,H.J.Zur Entwicklung der Ganztagsschule in der Bundesrepublik Deutschland. Forum E, [S.1: s.n.], v. 41, n. 9, p. 8-13, set. 1988. [Sobre o desenvolvimento da escola em tempo integral na República Federativa da Alemanha]

Kamsкi, I. Innerschulische Kooperation in der Ganztagsschule: Eine Analyse der Zusammenarbeit von zwei Berufsgruppen am Beispiel von Lehrkräften und Erzieherinnen und Erziehern. Münster: Waxmann, 2011. [Cooperação relacionada com a escola em tempo integral: uma análise da cooperação entre dois grupos de profissionais no exemplo de professores(as) e educadores(as)]

Kamski, I.; Koltermann, S.; Krinecki, J. 99 Tips: Ganztagsschule. Berlin: Cornelson, 2013. [99 dicas: escola em tempo integral]

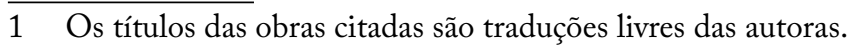


KMK - Kultusminister Konferenz. Bericht über die allgemein bildenden Schulen in Ganztagsform in den Ländern der Bundesrepublik Deutschland: Schuljahre 2002/2004. Berlin: KMK, 2006. Disponível em: <https:/www.kmk.org/fileadmin/pdf/Statistik/ GTS_2004.pdf >. Acesso em: 28 jul.2018. [Relatório sobre as escolas da educação básica em Escolas em Tempo Integral nos estados da República Federativa da Alemanha: anos letivos 2002/2003]

. Allgemein bildende Schulen in Ganztagsform in den Ländern in der Bundesrepublik Deutschland: Statistik 2003 bis 2007. Berlin: KMK, 2009. Disponível em: <http://www. kmk.org/fileadmin/pdf/Statistik/GTS_2007.pdf>. Acesso em: 20 jun. 2015. [Escolas da educação básica em tempo integral nos estados da República Federativa da Alemanha: estatística de 2003 a 2007]

.Allgemein bildende Schulen in Ganztagsform in den Ländern in der Bundesrepublik Deutschland: Statistik 2009 bis 2013. Berlin: KMK, 2015. Disponível em: <http://www. kmk.org/fileadmin/pdf/Statistik/GTS_2013_Bericht.pdf>. Acesso em: 20 jun. 2015. [Escolas da educação básica em tempo integral nos estados da República Federativa da Alemanha: estatística de 2009 a 2013]

Lohmann, H. Das Problem der Ganztagsschule: Eine historisch-vergleichende und systematische Untersuchung. Ratingen: Henn, 1965. [O problema da escola em tempo integral: uma análise histórico-comparativo e sistemática]

Ludwig, H. Entstehung und Entwicklung der modernen Ganztagsschule in Deutschland. Köln: Böhlau, 1993. [O surgimento e o desenvolvimento da escola em tempo integral moderna na Alemanha]

Die Entstehung und Entwicklung der modernen Ganztagsschule in Deutschland: ein historischer Überblick in systematischer Absicht. In: Rekus, J. (Org.). Ganztagsschule in pädagogischer Absicht. Münster: Aschendorff, 2003. p. 2848. [O surgimento e o desenvolvimento da escola em tempo integral moderna na Alemanha: uma visão histórica para fins sistemáticos] [Escola em tempo integral para fins pedagógicos]

Parente, C. M. D. Educação em tempo integral e Programa Mais Educação: aproximações e distanciamentos das regiões brasileiras em relação à meta prevista no projeto de lei do novo Plano Nacional de Educação (PNE). Revista Contrapontos, Itajaí: Univali, v. 14, n. 3, p. 619-633, set./dez. 2014. Disponível em: <www.univali.br/ periodicos>. Acesso em: 5 maio 2015.

Rekus, J. Braucht die Ganztagsschule eine spezifische Schultheorie? In: Rekus,J.(Ed.). Ganztagsschule in pädagogische Verantwortung. Münster: Aschendorf, 2003. p. 86-100. [A escola em tempo integral precisa de uma teoria escolar específica?] [Escola em tempo integral na responsabilidade pedagógica]

Rollett, W. Escola em tempo integral na Alemanha: ampliação e consolidação, justificativa baseada em argumentos político-educacionais e fundamentos teóricos. In: Seminário Nacional de Política e Gestão da Educação, 3.,2014; Encontro Internacional de Pesquisa Empírica em Educação, 1, 2014, São Cristóvão. Anais eletrônicos... São Cristóvão: UFS, 2014, p. 10-21. Tema: A escola em tempo integral. 
Schnetzer, T. Zeitstrukturierung an Ganztagsschulen. In: Kamski, I.; Holtappels, H. G.; Schnetzer, T. Qualität von Ganztagsschule: Konzepte und Orientierungen für die Praxis. Münster: Waxmann, 2009. p. 100-109. [Estruturação do tempo em escolas em tempo integral] [Qualidade da escola em tempo integral? Concepções e orientações para a prática]

Sonnentag, S.; Fay, D.; Frese, M. Handeln in Organisationen. In: Schuler, H. (Org.). Organisationspsychologie: Gruppe und Organisation. Enzyklopädie der Psychologie, Göttingen, Ber. Toronto, Seattle: Hogrefe, 2004. [Agir em organizações] [Psicologia de organicações: grupos e organisation. Enciclopédia da psicologia]

\section{SOBRE AS AUTORAS}

Heike Schmitz é doutora em educação pela Universidade Federal da Bahia (UFBA). Professora da Universidade Federal de Sergipe (UFS).

E-mail: hs.contato.ufs@gmail.com

Ilse Kamski é doutora em educação pela Technische Universität Dortmund (Alemanha). Pesquisadora da mesma instituição.

E-mail: ilse.kamski@tu-dortmund.de

Recebido em 7 de fevereiro de 2017

Aprovado em 3 de julho de 2017 